Published online in Wiley InterScience (www.interscience.wiley.com). DOI: 10.1002/mde.1192

\title{
Resources, Capabilities, and the Performance of Industrial Firms: A Multivariate Analysis
}

\author{
Abraham Carmeli $^{\mathrm{a}}$ and Asher Tishler ${ }^{\mathrm{b}, *}$ \\ ${ }^{a}$ Graduate School of Business Administration and Department of Political Science, Bar-Ilan University, \\ Ramat-Gan 52900, Israel \\ ${ }^{\mathrm{b}}$ Faculty of Management, Tel Aviv University, Ramat Aviv, Tel Aviv 69978, Israel
}

\begin{abstract}
This study uses multivariate analysis to assess the basic question asked by resource-based view researchers: Do organizational resources and capabilities account for variations in firm performance? An analysis of survey responses of 93 industrial enterprises in Israel indicates that superiority of an industrial enterprise, in terms of four performance measures (return on sales, return on equity, market share change, and customer satisfaction), can be explained by a set of four core organizational resources and capabilities (managerial skills, organizational culture, organizational communication, and perceived organizational reputation). The results lend significant support to the premise of the resource-based view of strategic management. Copyright (C) 2004 John Wiley \& Sons, Ltd.
\end{abstract}

\section{INTRODUCTION}

Much effort has been directed in the last decade to the theoretical foundations of the resource-based view (RBV) of strategic management. However, this approach has been criticized and its standing as a paradigm in the field of strategy has been questioned (Priem and Butler, 2001) inter alia on the grounds that the theory has not been sufficiently supported by empirical analysis (see Farjoun, 1994). In particular, it has been argued that more empirical research is needed in order to: (a) capture the multi-dimensionality of performance; and (b) estimate the effect of a bundle of resources and capabilities on firm performance. Robins and Wiersema (1995; 292-293), for example, pointed out that 'many of the strategic characteristics of firms identified by resourcebased theory cannot be measured directly [and]

*Correspondence to: Faculty of Management, Tel Aviv University, Ramat Aviv, Tel Aviv 69978, Israel. E-mail: atishler@post.tau.ac.il operationalization of the theory requires approaches rooted in the behavioral sciences'. Indeed, though the study of Hitt and Ireland (1985) was a promising start, little empirical work has been done since then to address the basic question of the relative effects of organizational resources and capabilities, environmental constraints, and structural factors (number of employees, volume of sales, etc.) on the performance of industrial firms.

To fill this gap, the present study of 93 Israeli firms in a variety of industries quantitatively tests the influence of a set of intangible resources and capabilities (managerial skills, human capital, perceived organizational reputation, internal auditing, organizational culture, and organizational communication) on overall firm performance (represented by four performance measures: return on sales, return on equity, market share change, and customer satisfaction) while controlling for the effects of environmental uncertainty, sector type, and organizational size. Instead of examining the effect of a single resource 
on a single measure of performance of firms in a single industry, as most studies have done, this study adopts a multivariate approach in which several organizational resources and capabilities are examined simultaneously for their influence on several measures of performance of firms in a variety of industries. This approach to testing the effects of organizational resources and capabilities on performance may strengthen the theoretical insights of the resource-based view.

The findings are consistent with the basic insight of the resource-based view. Out of the six organizational resources and capabilities that were examined, four were critical in explaining the variations in firm performance. The most critical resource was perceived organizational reputation, second in importance was managerial skills of the firm's top management, the third was organizational culture, and fourth was organizational communication. The two other resources and capabilities that were tested (human capital and internal auditing) and the control variables did not have much effect on the variability of firm performance.

We begin with the theoretical and methodological aspects of the resource-based view. We then develop the main research question and the research hypotheses. The research method-participants, measures, and data analysis - is presented in the subsequent section. Finally, the results of the study are presented and analyzed, followed by a discussion of its limitations, and suggestions for directions of future research.

\section{THEORETICAL AND METHODOLOGICAL BACKGROUND}

The theoretical foundations of the RBV can be found in various studies in the field of strategy (e.g., Penrose, 1959; Hofer and Schendel, 1978; Hitt and Ireland, 1985). The RBV suggests that researchers devote their attention to analyzing the performance of firms in terms of their resources, rather than their product market activities (Wernerfelt, 1984), since distinctive organizational resources, capabilities, and competencies generate a sustainable competitive advantage and lead a firm to above-normal performance (see Hofer and Schendel, 1978; Prahalad and Hamel, 1990). Each firm possesses a different profile of tangible and intangible resources and capabilities (Reed and DeFillippi, 1990; Barney, 1991; Amit and Schoemaker, 1993; Peteraf, 1993). Differences in profiles among firms account for variations in the firms' competitive position and their performance (Prahalad and Hamel, 1990; Reed and DeFillippi, 1990).

Resource as a general term is taken to include three main constructs - resources, capabilities, and competencies, which have been variously defined in the strategic management literature, making it difficult to generalize results across studies. The following definitions are used in the current study. Resources are 'stocks of available factors that are owned or controlled by the firm' (Amit and Schoemaker, 1993; 35). Capabilities refer to 'a firm's capacity to deploy resources, usually in combination, using organizational process to effect a desired end' (Amit and Schoemaker, 1993; 35). Competencies are 'the particular skills and resources a firm possesses and the superior way in which they are used' (Reed and DeFillippi, 1990; 90). These definitions suggest that resources are input based, capabilities are functional or process based, and competencies are cross-functional and based on process integration.

The contribution of the resource-based view to strategic management is its emphasis on firmspecific resources as the real source of sustainable competitive advantage and above-normal performance (Wernerfelt, 1984; Reed and DeFillippi, 1990; Barney, 1991; Teece et al., 1997). As Collis and Montgomery $(1998 ; 27)$ say, resources are 'the substance of strategy, the very essence of sustainable competitive advantage', Gaining superiority in a competitive market depends on a firm's ability to identify, develop, deploy, and preserve particular resources that distinguish it from its rivals (Dierickx and Cool, 1989; Amit and Schoemaker, 1993). Resources and capabilities that have high value (i.e., contribute to improving the firm's performance) and rareness (i.e., are possessed by fewer of the firms than the number necessary to create perfect competition dynamics) have the potential to create competitive advantage (Barney, 1991). In order to produce a sustainable competitive advantage, resources and capabilities should be characterized as highly valuable, rare, inimitable (i.e., they are costly to copy by competitors), nonsubstitutable (i.e., no substitute to fulfill the same function is immediately available to competitors) (Barney, 1991) and nontransferable (i.e., they 
cannot easily be purchased) (see Dierickx and Cool, 1989).

\section{Current Difficulties in Studying the Resource-based View}

Recently, scholars in the field of strategic management have been examining the merits of the RBV as a paradigm. Most importantly, they have argued that the RBV does not presently appear to be capable of supporting a theoretical model insofar as it fails to meet the empirical criterion (Priem and Butler, 2001). For example, in questioning the potential of the RBV as a paradigm in the field, Peteraf $(1993 ; 179)$ asks whether it 'provides much additional insight over traditional understandings'. Although Peteraf (1993) and others (Barney, 2001) have advocated it, the debate has not yet been resolved. One area of criticism is the need for more empirical studies testing the basic insights and definitions of the theoretical model (see Farjoun, 1994; Yeoh and Roth, 1999). In particular, 'the recent advance of the RBV has posed new challenges regarding the use of quantitative methods' (Hoskisson et al., 1999; 447).

More specifically, the design of most empirical RBV studies suffers from some of the following limitations: (1) the use of a single major factor to explain variation in firm performance; (2) the use of a sample of firms from a single industry (without providing strong support that the investigated resources are industry specific); and (3) the examination of each performance measure separately. Most quantitative studies have used a single resource such as human capital (e.g., Hitt et al., 2001) or leadership (e.g., Waldman et al., 2001). Although such studies yield some useful knowledge, it must be recognized that competitive position is derived from a combination of several resources and capabilities. It is not likely that a firm with a sustainable competitive advantage relies on a single factor, important as it may be. For example, the competitive advantage of WalMart cannot be explained by just one factor; it is based on a successful integration of several resources and capabilities. Clearly, a major problem in using a set of resources and capabilities is that strategic resources and capabilities are, by nature, intangible and difficult to measure (see Godfrey and Hill, 1995; Hitt et al., 2001). This is true for even a single intangible resource,

Copyright (C) 2004 John Wiley \& Sons, Ltd. and the difficulty is compounded when more than one is involved. Analyzing RBV within a single industry, such as the movie industry (e.g., Miller and Shamsie, 1996) or pharmaceuticals (e.g., Yeoh and Roth, 1999), has its merits. First, the primary interest of RBV is competitive advantage, and this may, by definition, be an intra-industry phenomenon. Second, resources and capabilities are industry-specific and cannot easily be transferred across industry boundaries. Third, by studying a single industry the researcher eliminates the need to measure and control for the broad range of industry-specific factors. Although studies in a single industry advance our knowledge, generalization from them is questionable because of 'the uniqueness of an industry's environment' (Dess et al., 1990; 13). Only a few empirical studies (e.g., Hitt and Ireland, 1985; Markides and Williamson, 1994; Robins and Wiersema, 1995) have tested companies from a variety of industries. For example, the study of Robins and Wiersema (1995), which was conducted among 88 firms listed in the Fortune magazine and acting in a variety of industries, indicated that the resource-based view has accounted for variance in financial performance. To our knowledge, the influential study of Hitt and Ireland (1985) is unique in combining distinctive competencies and firms from a variety of industries. These researchers examined the relationships of seven distinctive functional competencies, consisting of 55 activities, to market returns of 185 Fortune 1000 firms in a variety of industries. However, Hitt and Ireland, 1985, like other researchers (e.g., Chatterjee and Wernerfelt, 1991) used correlation and regression procedures to test their hypotheses. These procedures limit the test of the role of resources in generating competitive advantage and above-normal performance because (1) the dependent variables are examined separately and (2) a weight is not assigned to each resource and capability within a specific set of variables.

In summary, it seems more useful to test several performance measures simultaneously than to test each one separately. The results clarify the influence of a set of independent variables on a set of dependent variables. The issue is how. This study attempts to overcome some of the limitations of previous studies by adopting a multivariate approach in which a bundle of resources and capabilities of firms in a variety of industries 
are examined for their simultaneous effect on several measures of performance.

\section{THE RESEARCH QUESTION AND THE RESEARCH HYPOTHESES}

Resources can be classified into two basic categories: tangible and intangible. Tangible resources are the physical items an organization possesses, such as facilities, raw materials, and equipment. Intangible resources are items such as skills, knowledge, perceptions, and processes that cannot be listed in regular managerial-accounting reports. Intangible resources have always been considered to play an important role in firms' value creation. As pointed out by Canals $(2000 ; 118)$ 'as the industrial society becomes a services society, where knowledge and information are the mainstays of business growth, the importance of intangible resources will come increasingly to the forefront'. Compared with tangible resources, intangible resources such as reputation or organizational culture are less flexible (Chatterjee and Wernerfelt, 1991), hard to accumulate, and not easily transferred; they can be in multiple uses simultaneously, serve simultaneously as inputs and outputs of corporate activities (Itami and Roehl, 1987), and are not consumed when in use (Collis and Montgomery, 1998). Teece (2000) says that a firm's superior performance depends on its ability to innovate, defend intangible assets (e.g., knowledge), and use those assets. According to Hitt et al. (2001; 14), 'intangible resources are more likely than tangible resources to produce a competitive advantage'. Drawing on these insights, this study focuses on a set of intangible resources and capabilities.

Many scholars view the behavior of an organization as a function of the external environment, and for many years researchers focused on the effects of environmental opportunities and threats on firm performance. These researchers consider the task environment a source of competitive advantage and superior performance (Porter, 1980; Dess and Beard, 1984). Porter (1980) suggests that the collective effects of five environmental forces set the rules of competition of an industry, which determine a firm's competitive strategy and ability to attain its goals. The relationship between environment and effective- ness forces the organization to be an open system of inputs and outputs. It is likely that closed systems are short lived because, unlike open systems, which delay entropy through import of crucial energies from the external environment, closed systems do not make exchanges with their environment. Organizations compete for resources that make their existence possible and only those that can make themselves compatible with their task environment avoid mortality.

To examine the effects of an industry, Dess and Beard $(1984 ; 64)$ suggested that an industrial classification would provide useful building blocks to improve the conceptualization and measurement of organizational task environments. This study identifies two aspects of the task environment and tests their influence on firm performance: environmental uncertainty, and industrial sector. Environmental uncertainty is defined as the perception of a firm's top management regarding their ability or inability to comprehend the future direction of their task environment. In an uncertain competitive environment, a firm has difficulty in understanding what will be its future direction. Sector type is defined as whether a firm is in a high-tech or low-tech industry. ${ }^{1}$ Environmental uncertainty and industrial sector have been widely discussed in the literature, but little has been done to test them quantitatively. Organizational structural factors are also recognized as affecting performance, and one such factor-organizational size - is identified. Thus, the basic research question of the study is:

How much do organizational resources and capabilities matter for explaining variations in firm performance relative to environmental uncertainty, sector, and organization size?

As the environment generates constraints for all the players in an industry, it is most likely that only the 'fit' firms (see Itami and Roehl, 1987) will be in an advantageous competitive position and achieve above-normal performance (i.e., return). Compatibility with an industry's opportunities and threats depends on the competitive advantage of the firm, which depends on its resources and capabilities. For example, Hansen and Wernerfelt (1989) found that the external market factors independently explain variance in performance, but that internal factors can explain it twice as well. 
Six resources and capabilities are examined: managerial skills, human capital, and perceived organizational reputation are the resources, and internal auditing, organizational culture, and organizational communication are the capabilities. A brief explanation is given of why these variables were selected for testing as predictors of variations in firm performance.

\section{Managerial Skills}

The notion that top management plays a significant role in generating rent for a firm has long been established both theoretically and empirically (Penrose, 1959; Katz, 1974; Hambrick and Mason, 1984; Norburn and Birley, 1988; Barney, 1991; Castanias and Helfat, 1991; Finkelstein and Hambrick, 1996). Top management may be defined as the CEO or as the CEO and other senior managers. This study attempts to reach a better understanding of how managerial skills, defined as the set of the entire top management team's integrated skills, affect firm performance (Hambrick and Mason, 1984). According to Barney $(1991 ; 117)$, the ability of managers 'to understand and describe the economic performance potential of a firm's endowments' rests on an integration of skills. Katz (1974; 91) suggests that an effective administration rests on three types of skills: technical, human, and conceptual. The best managers are those who make the transition from administrative management to institutional leadership and hold the managerial skills that are the cornerstone of successful leadership (Yukl, 1981).

For a firm to gain superiority requires that top management possess a broad set of complementary skills. A single person, however talented, is unlikely to possess all the managerial skills that are required for the successful operation of a large organization. A range of managerial skills enables a firm to deploy specific skills to cope with specific situations. Mahoney $(1995 ; 92)$ pointed out that 'the attributes of the management team may satisfy the conditions for achieving and maintaining competitive advantage', but he also noted that only 'managerial skills in combination with other firm resources can jointly produce rents'. Technical, human, and conceptual skills are not equally important in all industries and leadership situations (see Katz, 1974; Yuk1, 1981; Castanias and Helfat, 1991), but all three are important in some combination to build a superior management team.

\section{Human Capital}

The notion of the importance of the human factor in organizational efficiency and effectiveness and the idea that an organization's members are the real source of its competitive advantage (Pfeffer, 1994) spring from the human relations movement and from several other perspectives. (1) Transaction cost economics holds that an organization looks for the optimal way to manage the human resources system, which depends on both the transaction cost related to the market-organization relationship and the internal side of the organization (Williamson, 1975). (2) Human capital theory focuses on the education and training level of employees as a source of a labor productivity and economic growth (Schultz, 1961; Becker, 1993; Asefa and Huang, 1994). It is worth noting that although most research focuses on the organization level, human capital is also an important resource on the national level (see Hershberg, 1996). (3) The resource-based view holds that employees' skills are a strategic resource. Strategic human resource management researchers have directed considerable attention to the link between the management of human resources and the competitive advantage of an organization (e.g., Farjoun, 1994; Lado and Wilson, 1994; Pfeffer, 1994; Boxall and Steeneveld, 1999). As pointed out by Pfeffer (1994: 21) 'if work force is, indeed, an increasingly important source of competitive advantage, then it is important to build a work force that has the ability to achieve competitive success and that cannot be readily duplicated by others'. In particular, a dominant approach in the strategic human resource management approach has been directed to the link between human resource management practices and firm performance (e.g., Huselid, 1995). In this regard, it should be noted that a distinction is made between the organization's human resources as such and human resources as the organization's function or practices. This study focuses on the output of the human resources management processes, that is, the organization's human capital and its importance to the firm's performance.

Human capital, as defined here, has three dimensions: education, work experience, and 
competence (Aryee et al., 1994). Whereas education and work experience are commonly used as ingredients of human capital, only rarely is attention directed to the four subfactors of competence: (1) the sense of being part of the surrounding Gestalt and subjectively feeling competent; (2) task knowledge and problem solving capabilities; (3) external influence, that is, the ability to control one's own work setting rather than needing external control; and (4) confidence, that is, trust in one's own abilities and feelings (Wagner and Morse, 1975).

\section{Internal Auditing}

Internal auditing is a process that examines and evaluates the functioning of the organization (Eden and Moriah, 1996; 263). It is an ongoing process of comparing actual performance with standards or expectations, based on relevant indexes in order to improve the organization's achievements (Globerson and Globerson, 1990). Internal auditing was long a neglected topic in organization research. In the 1940s the Institute of Internal Auditors (IIA) formulated standards, but it was not until the 1970s that the IIA suggested that organizations meet those standards to obtain the internal auditors' approval (see Eden and Moriah, 1996). One of the problems was that the audit was viewed as a tool for punishment and enforcement, rather than a constructive means to improve the organization's performance. Researchers and practitioners have only recently begun to acknowledge internal auditing as an important tool in managing the organization efficiently and to view the audit's products as constructive rather than destructive. Eden and Moriah (1996) suggest that an internal auditing system might be expected to improve the effectiveness of a firm by (1) teaching the organization's members how to execute their job better by pointing out weaknesses, (2) enhancing the motivation of the organization's members by demonstrating that the audit's goal is improving the efficiency and effectiveness of the organization, (3) deterring members from actions that might damage the organization, and (4) improving the probability that the appropriate actions are taken in relation to goal setting and accomplishment.

\section{Organizational Culture}

Organizational culture refers to the 'underlying values, beliefs, and principles that serve as a foundation for an organization's management system as well as the set of management practices and behaviors that both exemplify and reinforce those basic principles' (Denison, 1990; 2). Strategy researchers are interested in organizational culture for the role it has in the creation of competitive advantage. Porter (1980) used the case of Clark Equipment to argue that firms with below-normal return suffer from ambiguous and unclear organizational culture. Barney (1986) claimed that as a valuable, rare, and imperfectly imitable resource, organizational culture is a source of sustainable competitive advantage. Fiol (1991) continued this approach, studying the interaction between values and practices as a source of competitive advantage. Klein et al. (1995) placed organizational culture at the heart of an organization's endeavors to improve its overall effectiveness and the quality of its products and services.

This study adopts the organizational culture model developed by Denison (1990). According to this model, organizational effectiveness depends on four integrated ingredients: (1) involvement of the organization's members, (2) a shared system of beliefs, values, and symbols among the organization's members, (3) the ability to adapt to the external environment and internal customers through a re-institutionalization of a set of behaviors and processes, and (4) a sense of mission, a shared definition of the function and purpose of an organization and its members. Many researchers argued for a positive relationship between organizational culture and variations in performance (Barney, 1986; Hansen and Wernerfelt, 1989; Denison, 1990; Marcoulides and Heck, 1993).

\section{Organizational Communication}

Organizational communication refers to a system by which an organization explains and clarifies task role requirements and organizational policies, and provides feedback to all its members (see Putti et al., 1990). Effective organizational communication may generate significant benefits; it 'enables an organization to begin a dialogue to create awareness, understanding, and appreciation for the firm's strategic goals' (van Riel, 2000; 157). 
Although the theoretical argument for the importance of organizational communication has been established, strategists have not invested much effort in investigating its importance in creating competitive advantage and generating above-normal performance (see Argenti and Forman, 2000). Tucker et al., (1996; 59) have pointed out the lack of empirical work testing the relationship between organizational communication and performance.

A firm can use various approaches to exploit its communication system. Recently, van Riel (2000) suggested that an organizational communication system that delivered coherent and appealing content would be more effective and better received by stakeholders. The importance that managers attribute to organizational communication is illustrated in several corporate anecdotes. For instance, one of the first moves Louis Gerstner made when he became CEO of IBM was to remedy what he saw as an ineffective communication system. His efforts are an acknowledgement of the importance of sharing available and reliable information among all organization members (see Finkelstein and Hambrick, 1996). The case of Sears, Roebuck, and Co. is also an insightful example of the advantage firms can gain from an effective organizational communication. CEO Arthur Martinez and his senior management team developed a new vision statement in the mid-1990s that was a radical departure from the company's earlier strategic direction: 'Sears: A compelling place to work, shop, and invest.' They devoted considerable attention to ensuring that the three constituencies implied in this vision statement -employees, customers, and investors - understood and internalized the new vision statement (Argenti and Forman, 2000; 235).

Organizational communication is related to the creation of knowledge, its dissemination, and the connection between the two processes (Tucker et al., 1996; 57). An effective communication system makes employees feel more involved in the overall processes. A feeling of belonging helps produce satisfied, committed, and productive employees, which eventually enhances the organization's performance.

\section{Perceived Organizational Reputation}

Organizational reputation is an intangible resource, representing an overall assessment of a firm's current assets, current position, and future performance (Teece et al., 1997; 521). A favorable organizational reputation is a core intangible resource that creates competitive advantage when competitors are not able to match the prestige and esteem it creates (Shrum and Wuthnow, 1988). It represents the outcome of a competitive process in which a firm signals its key characteristics to constituents in order to maximize its economic and non-economic (social, for instance) status (Fombrun and Shanley, 1990; 234). Constituents prefer to enter into a contract with a firm with a favorable reputation, and sometimes are even willing to pay a reasonable premium to do so (Weigelt and Camerer, 1988; Fombrun and Shanley, 1990; Fombrun, 1996). According to Fombrun (1996) and Fombrun and Shanley (1990), a favorable organizational reputation may generate competitive advantage for a firm by (1) delaying rivals' mobility and entry to the industry, (2) allowing a firm to charge premium prices, (3) attracting better applicants and better investors, (4) enhancing a firm's access to capital markets, (5) building strong morale among employees, and (6) improving both economic and non-economic results. Roberts and Dowling (1997; 75) state that "corporate reputation is an extremely important strategic asset [and] superior performers with favorable reputation are able to sustain superior outcomes for longer periods of time'.

An organization's reputation is distinct from construed external image (Dutton et al., 1994) or perceived external prestige (Smidts et al., 2001; Carmeli and Freund, 2002). Whereas organizational reputation refers to outsiders' beliefs about what distinguishes an organization, perceived external prestige and construed external image refer to the organization's members' view of the outsiders' beliefs. Accepting that the CEO as a representative of top management has the capability of correctly assessing the organization's reputation, we use the term perceived organizational reputation to mean top management's view of the outsiders' beliefs about the organization.

This logic and the examples above provide the basis for the following hypotheses:

I: Intangible resources and capabilities (managerial skills, human capital, internal auditing, organizational culture, organizational communications and perceived organizational reputation), taken together or independently, are an important 
resource for the firm to attain above-normal performance.

II: Organizational resources and capabilities are more important to firm performance than perceived environmental uncertainty, sector type, and organization size.

\section{THE DATA AND THE RESEARCH METHODOLOGY}

\section{Subjects and Data Collection}

The data used in this study were taken from a comprehensive research project that evaluated organizational competencies (organizational communication, organizational culture, internal control and others) of Kibbutz-owned industrial enterprises in Israel, Kibbutz being a collective settlement based on agriculture and industry (see Segev, 1987). The Kibbutz industries' share in Israeli industry amounts to $7 \%$ of sales, $9 \%$ of exports, $7 \%$ of investment, and $6.5 \%$ of industrial employment (Kibbutz Industries Association (KIA), 1999; http://www.kia.co.il/fabout.htm, 2001).

The research population was drawn from a list of the entire Kibbutz enterprises published by the Kibbutz Industries Association (1999). From the 385 industrial enterprises listed, we omitted very small enterprises and sub-units of larger businesses to arrive at a population of 300 industrial enterprises. The sample includes industrial enterprises from a variety of industries from the old economy (e.g., agriculture, food, textiles, steel, construction, paper and plastics) and the new economy (e.g., biotechnology, electronics, communication and pharmaceuticals); the variety is representative of Israeli industry.

Questionnaires were mailed from a university address to the enterprises' CEOs, who were asked to return them to the same address using a selfaddressed reply envelope. In order to encourage the CEOs to participate, we made two commitments in a cover letter. We guaranteed respondents complete anonymity, and we promised to deliver them the results and conclusions of the study. To increase the response rate, two mailings were sent out, the first in July 1999 and the second in August 1999. A total of 95 questionnaires was returned, yielding a response rate of approxi- mately $32 \%$, which is similar to previous studies of the same research population (Segev, 1987). Because of missing data two of the 95 questionnaires were not usable for the study. About 20\% of the enterprises were in the high-tech sector. The average age of the enterprises was 27.7 years (S.D. 15.2). The average number of employees was 94 . The average annual revenues were about 15 million US\$. The average age of the CEOs was 49 years (S.D. 7), and their mean tenure in the organization was 5.5 years (S.D. 4.4). All but one of the respondents were men. The majority of the CEOs $(87 \%)$ held at least a bachelor's degree; the others had 14 or less years of education.

\section{Measures}

The study investigates the influence of organizational resources and capabilities, environmental uncertainty, sector, and organization size on a set of firm performance measures.

\section{Dependent variables}

Firm performance. Four measures of firm performance were used: (1) return on sales (an accounting-based ratio of profitability) - ratio of net profit to net sales (revenues), the higher the ratio, the more profitable the firm (e.g., Waldman et al., 2001); (2) return on equity (an accountingbased ratio of profitability) - ratio of net profit to total equity investment, the higher the ratio, the more profitable the firm (e.g., Smith et al., 1994); (3) market share change-estimate of last year's change in the firm's market share, the higher a positive change, the more successful the firm; (4) customer satisfaction - an assessment of the extent to which the firm fulfills the customer's needs compared with its competitors (e.g., Collis and Montgomery, 1998). Each CEO was asked to rate his or her firm's performance relative to the performance of its competitors. Performance was rated on a five-point scale $(1=$ much worse than competitors, $2=$ worse than competitors, $3=$ as good as competitors, $4=$ better than competitors, $5=$ much better than competitors).

\section{Independent variables}

Managerial skills. This measure consists of the nine managerial skills identified by Yukl $(1981 ; 70)$ as characteristic of successful leaders; examples are cleverness, conceptual skills, and social skills. The CEOs were asked to evaluate to what extent the 
company's top management possesses these skills. Responses were on a 5-point scale ranging from $1=$ strongly disagree to $5=$ strongly agree. The Cronbach alpha for this scale was 0.81 .

Human capital. This measure has three dimensions: education, work experience, and competence of the firm's members (Aryee et al., 1994). The CEOs were asked to respond to four items relating to education and work experience and eight items relating to competence (Wagner and Morse, 1975). A sample item is 'In my company, employees have suitable education to fulfill their jobs'. The measure was assessed on a 5-point scale ranging from $1=$ strongly disagree to $5=$ strongly agree. The Cronbach alpha for this scale was 0.79 .

Internal auditing. This measure was based on the model developed by Eden and Moriah (1996). It includes four aspects of the auditing system: teaching, motivating, deterrence, and process improvement. A sample item is the internal auditing prevents inappropriate actions'. This measure was assessed on a 5-point scale ranging from $1=$ strongly disagree to $5=$ strongly agree. The Cronbach alpha for this scale was 0.71 .

Organizational culture. This measure is based on Denison's (1990) organizational culture model, which includes four hypotheses. (1) involvement hypothesis: organizational effectiveness is a function of the level of involvement and participation of the organization's members; (2) consistency hypothesis: organizational effectiveness is a function of the degree to which the organization's members understand and hold a shared system of beliefs, values, and symbols; (3) adaptability hypothesis: organizational effectiveness is a function of the organization's ability to perceive the external and internal environment and respond to it through a re-institutionalization of a set of behaviors and processes; (4) mission hypothesis: organizational effectiveness is a function of the degree to which the organization's members hold a shared definition of the function and purpose of the organization and its members. A mission enhances employees' connection with the organization and provides direction and goals that serve to define the appropriate course of action for the organization and its members. The eight items covering the four elements of the model were assessed on a 5-point scale ranging from $1=$ strongly disagree to $5=$ strongly agree. The Cronbach alpha for this scale was 0.82 .

Copyright (C) 2004 John Wiley \& Sons, Ltd.
Organizational communication. This measure is based on a 6-item scale developed by Petty et al. (1989). A sample item is 'Usually, our employees hear information from the public media sooner than they hear it through official channels' (reverse scored). The respondents were asked to assess six items on a 5-point scale ranging from $1=$ strongly disagree to $5=$ strongly agree. The Cronbach alpha for this scale was 0.67 .

Perceived organizational reputation. The items of this measure are based on Fortune's America's Most Admired Corporations index, compiled from an annual survey asking 8000 top executives, outside directors, and financial analysts to rate the ten largest companies in their own industry on eight attributes, using a scale of 0 (poor) to 10 (excellent) (e.g., Smith, 1990). The Fortune index has been used in many studies (e.g., McGuire et al., 1988; Fombrun and Shanley, 1990; Fryxell and Wang, 1994). Some studies use all the components of this index to evaluate overall corporate reputation (e.g., Fombrun and Shanley, 1990; Fryxell and Wang, 1994), while others use only four components to evaluate aspects of corporate social responsibility (e.g., Hammond and Slocum, 1996; McGuire et al., 1988). In this study, CEOs were asked to rate their companies on the eight attributes such as innovativeness and use of firm's assets. The measure was assessed on a 5-point scale ranging from $1=$ strongly disagree to $5=$ strongly agree. The Cronbach alpha for this scale was 0.76 .

\section{Control variables}

Environmental uncertainty. The environmental uncertainty measure used here was developed by Miller and Droge (1986), and has been discussed and examined in organization research (e.g., Waldman et al., 2001). The measure consists of five items, a sample item being 'our firm must rarely change its marketing practices to keep up with the market and competitors'. It was assessed on a 5-point scale ranging from $1=$ strongly disagree to $5=$ strongly agree. The Cronbach alpha for this scale was 0.68 .

Sector. This measure is included to control for technology variations across industries; high-tech industries are presumed to be more uncertain and possibly more unstable than low-tech industries. The sector is represented by a dichotomous variable with a value of 1 to denote a high-tech industry (communication, biotechnology, electronics, and pharmaceuticals) and 0 to denote 
Table 1. Means and Standard Deviations of the Variables of the Study

\begin{tabular}{lcc} 
& Mean & $\begin{array}{r}\text { Standard } \\
\text { deviation }\end{array}$ \\
\hline Return on sales & 3.33 & 1.00 \\
Return on equity (ROE) & 3.40 & 1.05 \\
Change in market share & 3.33 & 0.93 \\
Customer satisfaction & 3.74 & 0.64 \\
Environmental uncertainty & 2.85 & 0.70 \\
Organizational size (annual income & 14.40 & 20.34 \\
in million \$) & & \\
Managerial skills & 3.21 & 0.47 \\
Human capital & 3.52 & 0.43 \\
Internal auditing & 3.82 & 0.44 \\
Organizational culture & 3.46 & 0.51 \\
Organizational communication & 3.55 & 0.48 \\
Perceived organizational reputation & 3.53 & 0.57 \\
\hline
\end{tabular}

a low-tech industry (food, agriculture, textiles, steel, construction, paper, and plastics).

Organization size. This measure was included to control for variations in the size of the firms in the sample, size being represented by the organization's revenues in the previous year.

Table 1 presents the means and standard deviations of the variables that were used in this study.

\section{The Multivariate Analysis Approach}

Multivariate analysis is often employed when researchers need to represent a very large data set by several, easy-to-interpret variables or when it is necessary to relate one set of variables to other sets of variables. This method facilitates the identification of the effects of key variables in one data set on all or several of the variables in other sets.

There are several types of multivariate analysis. In the case of two or more data sets, canonical correlation analysis (CCA) has been successfully used in different applications in the behavioral, social and economic sciences (Timm, 1975; Dillon and Goldstein, 1984; Cliff, 1987; Tishler et al., 1996). However, when the number of variables in one of the data sets is large, which is often the case, the weights obtained by CCA may be unreliable. To circumvent these problems and obtain reliable and robust weights Tishler and Lipovetsky (2000) developed and applied the method of robust canonical analysis (RCA), which has been used successfully in management applications (Tishler et al., 1996; Ahituv et al., 1999; Tishler and Lipovetsky, 2000; Wegelin, 2000).

Canonical analysis: setup and notation. Suppose that we are given two sets of data, each organized in a matrix, as follows: $X_{i j}, i=1, \ldots, l ; j=1, \ldots$, $n$, and $Y_{i j}, i=1, \ldots, l ; j=1, \ldots, m$. In the field of management, each data set may include a group of specific variables describing various attributes of $l$ firms or assessments of $l$ individuals. For example, $X$ may represent data on $n$ variables describing the information system characteristics of the firm and $Y$ may contain $m$ different performance measures of the firm (see Ahituv et al., 1999; Tishler et al., 1996). For ease of presentation, suppose that all variables are standardized (variables are standardized by subtracting their mean and dividing them by their standard deviations). Define the scores of the two data sets as follows:

$\eta=X \mathbf{a}, \quad \xi=Y \mathbf{b}$,

where $\mathbf{a}$ and $\mathbf{b}$ are $(n \times 1)$ and $(m \times 1)$ vectors of constant weights (parameters). The $(l \times 1)$ vectors of scores $\eta$ and $\xi$ can be interpreted as the weighted averages of their respective matrices (sets of variables). For example, $\xi$ includes the average values of the different performance measures; that is, a relatively high value of $\xi_{1}$ means that the overall (average) performance of firm 1 is very high relative to other firms in the sample. In this paper we try to find the relations, or connections, between data sets $X$ and $Y$ by means of the weighted averages ('aggregators') $\eta$ and $\xi$; that is, we say that $X$ and $Y$ are closely related to each other if $\eta$ and $\xi$ are 'close' to each other. Clearly, the weights $\mathbf{a}$ and $\mathbf{b}$ may have managerial or other meanings that should be taken into account in the analysis.

RCA uses covariance as the measure of connection between two data sets; that is, RCA seeks to estimate $\mathbf{a}$ and $\mathbf{b}$ that maximize the following sample covariance:

$\max _{\mathbf{a}, \mathbf{b}} \equiv \operatorname{cov}(\xi, \eta)=\xi^{\prime} \eta=\mathbf{a}^{\prime} X^{\prime} Y \mathbf{b}$,

with the usual normalizing conditions $\mathbf{a}^{\prime} \mathbf{a}=\mathbf{1}$ and $\mathbf{b}^{\prime} \mathbf{b}=1$. Thus, applying the RCA method to two data sets amounts to estimating the weights that maximize the covariance between the linear aggregators (weighted averages) of the two data sets. Variables in one data set are defined as critical (important) relative to those in the second data set when their weights in the RCA between the two 
data sets are large (see Tishler et al., 1996; Tishler and Lipovetsky, 2000 for algorithms that select critical variables from large data sets). Variables that are not designated as critical relative to the other data set may still affect this set. However, their influence on the second data set may not be as pronounced as the influence of critical variables.

\section{RESULTS}

This section presents and analyzes the results of the main research question and hypotheses. RCA was employed to estimate the vectors $\mathbf{a}$ and $\mathbf{b}$ (see Equation (2)) in the presence of all the performance measures and all the control and independent variables. The critical (i.e., important) variables in each of the two groups (the dependent variables in the matrix $Y$ and the independent variables in the matrix $X$ ) are those with 'large' absolute values (these variables are identified by means of the algorithm in Tishler and Lipovetsky, 2000, and Tishler et al., 1996). The estimates of the RCA with all the research variables are presented in Table 2.

The results, shown in Table 2, indicate some preliminary support for Hypothesis II, which predicts that the intangible resources and capabilities will be more critical than the control variables in explaining the variation in firm performance. The critical variables, those with the larger values in the vector a, were perceived organizational reputation, managerial skills, organizational culture and organizational communication. Note that perceived environment uncertainty, organizational size and human capital have some effect on firm performance, whereas sector and internal auditing exhibit no effect on the items representing perfor- mance. It may be suggested that larger firms perform somewhat better than smaller firms, firms that operate in a more certain task environment may perform better than those acting in an uncertain task environment and that firms with a higher level of human capital may perform better than those with a lower level. The estimation results indicate that, in our sample, the latter variables have a relatively small effect on the firm's performance. These initial findings suggest a clear answer to the research question and hypotheses. Intangible resources and capabilities affect firm performance. Moreover, they affect firm performance more than environmental uncertainty, sector type, and organizational size.

The correlation between the estimated scores $\eta$ and $\xi$ (see Equation (1)) for the initial set of variables is 0.60 . This suggests that intangible resources are highly correlated with firm performance. A set of only four resources and capabilities (perceived organizational reputation, managerial resources, organizational culture and organizational communication) is found to be critical to the explanation of the variation in the set of firm performance measures. The correlation between the estimated scores of these four resources and capabilities with the set of four performance measures is 0.59 ; that is, these four resources and capabilities account for almost all of the explained variability in the set of the four performance measures that we employ. These results show strong support for the hypotheses of this paper and suggest that a combination of resources and capabilities possessed by a firm may play a significant role in creating competitive advantage, leading to superior firm performance.

The results in Table 2 reveal differences among the critical resources and capabilities in terms of

Table 2. The Relationships Between Organizational Resources and Capabilities, Perceived Environmental Uncertainty, Sector, Organizational Size and Firm Performance

\begin{tabular}{lllr} 
Performance measures & Vector b & Organizational resources and capabilities & Vector a \\
\hline Return on sales & 0.52 & Environmental uncertainty & -0.17 \\
Return on equity (ROE) & 0.56 & New economy & 0.10 \\
Change in market share & 0.54 & Organization size (natural log of sales) & 0.22 \\
Customer satisfaction & 0.37 & Managerial resources & 0.53 \\
& & Human capital & 0.25 \\
& & Internal auditing & 0.00 \\
& & Organizational culture & 0.39 \\
& & Organizational communication & 0.30 \\
& & Perceived organizational reputation & 0.57 \\
\hline
\end{tabular}

${ }^{\mathrm{a}}$ The model consists of all the variables that were used in the research. 
their importance to firm success. The most critical was perceived organizational reputation, with a value of 0.57 in the vector a. This finding clearly indicates that firms with a more favorable perceived organizational reputation hold a competitive advantage and gain above-normal performance. The second most critical independent variable is managerial skills, with a value of 0.53 in the vector a. This result indicates that a firm headed by a top management team characterized by a higher level of combined managerial skills is likely to have an advantage over other firms and be in a position to generate superior performance. Organizational culture, with a value of 0.39 in the vector $\mathbf{a}$, is third in importance. A firm with a strong culture embodied within and across the firm sub-systems is likely to achieve above-normal performance. The fourth most important independent variable is organizational communication, with a value of 0.30 in the vector a. A firm with effective organizational communication among all the organization's members is likely to achieve competitive advantage and abovenormal performance.

Finally, the estimates in Table 2 suggest that the resource human capital, perceived environment uncertainty and organizational size (with values of $0.25,-0.17$ and 0.22 , respectively) have some, albeit small, effect on firm performance, whereas sector type, and internal auditing exhibit no effect on the items representing performance. It may be suggested that highly skilled employees may have a small but positive contribution to the firm's performance. Moreover, firms that operate in a more certain task environment may perform better than those acting in uncertain task environment, and economies of scale indeed matter as they may augment the firm's ability to cope with volatile environments.

Three performance measures in Table 2 (return on sales, return on equity, market share change) have about the same weight. They have similar importance in forming this study's assessment of 'overall firm performance'. Customer satisfaction is critical in forming this assessment, although it is somewhat less important than the other three, possibly because it reflects overall success, rather than performance, of the firm (Lipovetsky et al., 1997, found that customer satisfaction is the most important indication of overall firm success).

Additional information may be obtained by performing RCA separately on each performance measure. The results of this estimation are presented in Table 3. Generally, the estimates in Table 3 exhibit patterns similar to those in Table 2. There are, however, some differences in the magnitudes of the effects of the predictors on each of the performance measures. Perceived environmental uncertainty is negatively associated with all four performance measures. However, it seems to have a critical effect only on customer satisfaction. In our sample, customer satisfaction is higher in firms belonging to the old economy; low-tech firms seem to outscore high-tech firms on this performance measure. Larger firms exhibit significantly higher returns on sales and higher ROE than smaller firms. Organizational size seems to exhibit a very small, but positive, effect on two performance measures: change in market share and customer satisfaction.

Table 3. The Relationships Between Organizational Resources and Capabilities, Perceived Environmental Uncertainty, Sector, Organizational Size and Firm Performance ${ }^{\mathrm{a}}$

\begin{tabular}{|c|c|c|c|c|}
\hline \multirow[b]{3}{*}{ Control and independent variables } & \multicolumn{4}{|c|}{ Dependent variable } \\
\hline & $\begin{array}{l}\text { Return } \\
\text { on sales }\end{array}$ & $\begin{array}{l}\text { Return on } \\
\text { equity (ROE) }\end{array}$ & $\begin{array}{l}\text { Change in } \\
\text { market share }\end{array}$ & $\begin{array}{l}\text { Customer } \\
\text { satisfaction }\end{array}$ \\
\hline & Vector b & Vector b & Vector $\mathbf{b}$ & Vector b \\
\hline Environmental uncertainty & -0.07 & -0.18 & -0.13 & -0.35 \\
\hline New economy & 0.18 & 0.19 & 0.16 & -0.35 \\
\hline Organization size (natural log of sales) & 0.33 & 0.26 & 0.08 & 0.13 \\
\hline \multicolumn{5}{|l|}{ Resources and capabilities } \\
\hline Managerial skills & 0.46 & 0.48 & 0.61 & 0.43 \\
\hline Human capital & 0.09 & 0.21 & 0.30 & 0.40 \\
\hline Internal auditing & -0.03 & 0.00 & 0.03 & 0.02 \\
\hline Organizational culture & 0.37 & 0.44 & 0.33 & 0.36 \\
\hline Organizational communication & 0.30 & 0.28 & 0.38 & 0.14 \\
\hline Perceived organizational reputation & 0.63 & 0.55 & 0.49 & 0.49 \\
\hline
\end{tabular}

${ }^{a}$ An RCA was performed separately for each dependent variable on all the control and independent variables. 
Table 3 confirms that organizational resources and capabilities are critical to all measures of firm performance. The effect of perceived organizational reputation is highest on return on sales and ROE, while the effect of managerial skills is highest on change in market share. The effect of human capital on the performance measures returns on sales and ROE is positive but small. It is important, however, for change in market share and customer satisfaction. Managerial skills are critical for all performance measures, but, as mentioned above, they are most critical to change in market share. Organizational culture is critical to all performance measures, with the highest effect on ROE. Similarly to the results in Table 2, we find that internal auditing is not critical to any of the performance measures.

\section{DISCUSSION}

This study is an empirical application of the theoretical foundations of the resource-based view (RBV) of strategic management. In particular, we have tried to bridge existing gaps between theory and reality by overcoming three limitations of previous studies: use of a single major factor to explain variation in firm performance, use of a sample from a single industry and the examination of each performance measure separately. Our study estimates the effect of a set of intangible resources and capabilities on a set of performance measures, as perceived by the firm's CEO, while controlling for the effects of environmental uncertainty, sector type and organization size, among industrial firms in a variety of industries. As suggested by Robins and Wiersema (1995), the use of a behavioral approach to operationalize the strategic characteristics of firms identified by resource-based theory enables us to measure these characteristics. Furthermore, the use of multivariate analysis enables us to test a combination of resources and capabilities, and determine their relative importance for firm performance. Hence, this study may make a significant contribution to the empirical side of the RBV. Our research methodology has the potential to provide a solid platform for future research, to support the theoretical foundations of the RBV, and to enhance understanding of the role resources and capabilities play in the creation of competitive advantage and superior performance for a firm.

The main hypothesis of this study is that intangible resources and capabilities are more critical to firm performance than environmental and structural factors. The findings strongly support the basic theoretical insight of the RBV; that is, gaining and preserving superiority in competitive markets depends on the set of core resources and capabilities that a firm has developed, acquired, and deployed in the competition arena (Amit and Schoemaker, 1993; Barney, 1991; Wernerfelt, 1984). The findings are consistent with the observation of Collis and Montgomery (1998; 27) that resources are 'the substance of strategy, the very essence of sustainable competitive advantage'. They, and other researchers, support the premise that intangible resources and capabilities may play a significant role in competitive advantage and value-added creation (see Canals, 2000; Chatterjee and Wernerfelt, 1991; Collis and Montgomery, 1998; Hitt et al., 2001; Itami and Roehl, 1987; Teece, 2000). The results are especially interesting because they reveal the effect of a set of intangible resources and capabilities on a set of performance measures and, thus, give added support to the resource-based insight that several resources and capabilities simultaneously affect variations in firm performance.

Four intangible resources and capabilities are found to play a significant role in generating competitive advantage and above-normal performance for a firm. Only one intangible resource, internal auditing, did not exhibit any effect on firm performance. The findings that perceived organizational reputation is the most important of the four is consistent with the idea that reputation represents the outcome of a competitive process in which firms signal their key characteristics to constituents in order to maximize their economic and non-economic status (Fombrun and Shanley, 1990). This result suggests that in the competitive process firms should dedicate much effort to establishing a favorable reputation.

Managerial skills of the top management are the second most critical intangible resource for success of a firm. This finding lends support to the notion that top management plays a significant role in generating rent for a firm (Castanias and Helfat, 1991; Hambrick and Mason, 1984; Finkelstein and Hambrick, 1996), and that managerial skills are the cornerstone of successful leadership 
(Yukl, 1981). Firms led by a team of managers with high levels of complementary skills are more likely to exhibit above-normal performance. However, it should be understood that only managerial skills in combination with other firm resources and capabilities can jointly produce rents (Mahoney, 1995; 92).

Organizational culture is the third most critical variable in explaining the variability of firm performance. This finding supports the premise that strong organizational culture is likely to generate sustainable competitive advantage (Barney, 1986). It is recommended that firms attempt to develop a culture that integrates members' involvement, shared beliefs, adaptability, and a sense of mission, as suggested by Denison (1990).

Organizational communication is the fourth critical resource. Although little has been done to test the effect of organizational communication on firm performance (see Tucker et al., 1996), the theoretical foundations for this relationship have a long history and there is some support for a positive relationship. For example, Azulay et al. (2002) found that top management's attitudes towards defense conversion differ from the employees' perceptions of these attitudes. According to these authors the discrepancy was due to a lack of commitment to conversion on the part of management and to ineffective organizational communication, which affected the fundamental plans of the organization to invest more effort in adapting defense projects to the civilian markets as part of the organizational adjustment to environmental constraints. The findings of our study support the argument of Smidts et al. (2001) that the organizational communication climate "could prove to contribute significantly to the (long-term) success of the company', and point to the need for more research on this important resource.

In our sample, human capital is not a critical resource. However, it does exhibit a positive, albeit small, effect on overall firm performance. This outcome is consistent with the observation that people are important for gaining superiority in a competitive market (Pfeffer, 1994). This is an important finding considering the fact that we assessed the overall human capital that a firm possesses, rather than individual capital (see Wright et al., 2001). Human capital has little or no effect on return on sales, but is important for the performance measures ROE, market share and customer satisfaction.

Copyright (C) 2004 John Wiley \& Sons, Ltd.
In conclusion, the results of this study support the basic insight of the RBV that firm's intangible resources and capabilities matter a lot for its competitive advantage and above-normal performance. They also indicate that future research could usefully examine the simultaneous use of several resources and capabilities. In addition, the results of this study represent the belief systems of the CEOs as they socially construct linkages among internal characteristics and relative performance. Thus, the RBV may not only be interpreted as an economically rational external view, but also in terms of what senior executives believe, which means that their strategic actions can be understood through their system of beliefs. The implication is that RBV may be used to predict aspects of organizational action in addition to long-term competitiveness. This interpretation of the RBV provides an explanation for the link between resources and capabilities and corporate strategy. The study also provides a research methodology for testing the theoretical foundations of the RBV and providing quantitative support for the theory.

The methodology of this study is based on an established body of literature in management science, but it is somewhat new in the strategic management field, so the data and results should be interpreted cautiously. Though multivariate analysis is a useful procedure to test the effect of resources and capabilities on multiple measures of firm performance, clearly, further empirical studies need to be carried out. A significant step forward would be to extend the present focus on intangibles by testing the effect of a combination of tangible and intangible resources and capabilities and their influence on firm performance. Furthermore, research should be expanded to other intangible resources and capabilities in a variety of industrial enterprises and in services.

Finally, as the study relies on questionnaire data, its empirical validity may be limited due to possible biases and reverse-causality/endogeneity problems. In addition, our results may suffer from self-selection in the data, as it is possible that the respondents had characteristics that differed from those of their counterparts who did not respond. While it is obvious that the exact differences cannot be known, one cannot rule out the possibility that the sample may not reflect all 385 firms. Yet, we believe that our data do not suffer significantly from this problem due to the fact that 
they cover all the industries in which Kibbutzowned firms compete. To better assess the potential problems due to reverse-causality/endogeneity, we took two steps. First, we used established measures for all the research variables. Second, we obtained objective information on the performance of several of the firms in the sample and compared it to the reported subjective performance measures. The objective and subjective performance measures were similar. Thus, biases due to reverse-causality/endogeneity problems may exist, but their effects on the outcome of this study are probably minimal.

\section{Acknowledgements}

The authors wish to thank Moshe Farjoun and an anonymous reviewer for many helpful comments and suggestions on earlier drafts of this paper.

\section{NOTES}

1. Using a set of industry dummies yielded the same results as using one dummy to distinguish the hightech sector from the low-tech sector.

\section{REFERENCES}

Ahituv N, Lipovetsky S, Tishler A. 1999. The relationship between firm's information systems policy and business performance: a multivariate approach. In Measuring Information Technology Investment Payoff: Contemporary Approach, Mahmood MA, Szewizak EJ (eds). Idea Group. Hershay, PA; 62-82.

Amit R, Schoemaker PJH. 1993. Strategic assets and organizational rent. Strategic Management Journal 14: 33-46.

Argenti PA, Forman J. 2000. The communication advantage: a constituency-focused approach to formulation and implementing strategy. In The Expressive Organization: Linking Identity, Reputation, and the Corporate Brand, Schultz M, Hatch MJ, Larsen MH (eds), Oxford University Press: Oxford; 233-245.

Aryee S, Chay YW, Tan HH. 1994. An examination of the antecedents of subjective career success among a managerial sample in Singapore. Human Relations 47(5): 487-509.

Asefa S, Huang WC (eds). 1994. Human Capital and Economic Development. W.E. Upjohn Institute for Employment Research: Michigan.

Azulay I, Lerner M, Tishler A. 2002. Converting military technology through corporate entrepreneurship. Research Policy 31: 419-435.

Barney JB. 1986. Organizational culture: can it be source of sustained competitive advantage? Academy of Management Review 11(3): 656-665.
Barney JB. 1991. Firm resources and sustained competitive advantage. Journal of Management 17(1): 99-120.

Barney JB. 2001. Is the resource-based 'view' a useful perspective for strategic management research? Yes. Academy of Management Review 26(1): 41-56.

Becker GS. 1993. Human Capital: A Theoretical and Empirical Analysis, with Special Reference to Education (3rd edn). The University of Chicago Press with The National Bureau of Economic Research: Chicago/London.

Boxall P, Steeneveld M. 1999. Human resource strategy and competitive advantage: a longitudinal study of engineering consultancies. Journal of Management Studies 36(4): 443-463.

Canals J. 2000. Managing Corporate Growth. Oxford University Press: New York.

Carmeli A, Freund A. 2002. The relationship between work and workplace attitudes and perceived external prestige. Corporate Reputation Review 5(1): 51-68.

Castanias RP, Helfat CE. 1991. Managerial resources and rents. Journal of Management 17(1): 155-171.

Chatterjee S, Wernerfelt B. 1991. The link between resources and type of diversification: theory and evidence. Strategic Management Journal 12: 33-48.

Cliff N 1987. Analyzing Multivariate Data. Harcourt, Brace and Jovanovich: New York.

Collis DJ, Montgomery CA. 1998. Corporate Strategy: A Resource-Based view. Irwin/McGraw-Hill: Boston, MA.

Denison DR. 1990. Corporate Culture and Organizational Effectiveness. Wiley: New York.

Dess GG, Beard DW 1984. Dimensions of organizational task environments. Administrative Science Quarterly 29: 52-73.

Dess GG, Ireland RD, Hitt MA. 1990. Industry effects and strategic management research. Journal of Management 16(1): 7-27.

Dierickx I, Cool K. 1989. Asset stock accumulation and sustainability of competitive advantage. Management Science 35(12): 1504-1511.

Dillon WR, Goldstein M. 1984. Multivariate Analysis, Methods and Applications. Wiley: New York.

Dutton JE, Dukerich JM, Harquail CV. 1994. Organizational images and member identification. Administrative Science Quarterly 39(2): 239-263.

Eden D, Moriah L. 1996. Impact of internal auditing on branch bank performance: a field experiment. Organizational Behavior and Human Decision Processes 68(3): 262-271.

Farjoun M. 1994. Beyond industry boundaries: human expertise, diversification and resource-related industry groups. Organization Science 5: 185-199.

Finkelstein S, Hambrick D. 1996. Strategic Leadership: Top Executives and Their Effects on Organizations. West Publishing Company: St. Paul, Minneapolis.

Fiol CM. 1991. Managing culture as a competitive resource: an identity-based view of sustainable competitive advantage. Journal of Management 17(1): 191-211. 
Fombrun CJ. 1996. Reputation: Realizing Value From the Corporate Image. Harvard Business School Press: Boston.

Fombrun CJ, Shanley M. 1990. What's in a name? Reputation building and corporate strategy. Academy of Management Journal 33(2): 233-258.

Fryxell GE, Wang J. 1994. The Fortune corporate 'reputation' index: Reputation for what? Journal of Management 20(1): 1-14.

Globerson A, Globerson S. 1990. Control and Evaluation in Organizations: Management by Measurement. Tel Aviv University: Israel.

Godfrey PC, Hill CWL. 1995. The problem of unobservables in strategic management research. Strategic Management Journal 16: 519-533.

Hambrick DC, Mason PA. 1984. Upper echelons: the organization as a reflection of its top management. Academy of Management Review 9: 193-206.

Hammond SA, Slocum Jr. JW. 1996. The impact of prior firm financial performance on subsequent corporate reputation. Journal of Business Ethics 15: $159-165$

Hansen GS, Wernerfelt B. 1989. Determinants of firm performance: the relative importance of economic and organizational factors. Strategic Management Journal 10: $399-411$.

Hershberg T. 1996. Human capital development: America's greatest challenge. Annals of the American Academy of Political Science 544: 43-51.

Hitt MA, Bierman L, Shimizu K, Kochhar R. 2001. Direct and moderating effects of human capital on strategy and performance in professional service firms: a resource-based perspective. Academy of Management Journal 44(1): 13-28.

Hitt MA, Ireland RD. 1985. Corporate distinctive competence, strategy, industry and performance. Strategic Management Journal 6: 273-293.

Hofer CW, Schendel D. 1978. Strategy Formulation: Analytic Concepts. West Publishing Company: St. Paul, MN.

Hoskisson RR, Hitt MA, Wan WP, Yiu D. 1999. Theory and research in strategic management: swings of a pendulum. Journal of Management 25(3): 417-456.

Huselid MA. 1995. The impact of human resource management practices on turnover, productivity, and corporate financial performance. Academy of Management Journal 38(3): 635-672.

Itami H, Roehl WT. 1987. Mobilizing Invisible Assets. Harvard University Press: Cambridge, MA.

Katz RL. 1974. Skills of an effective administrator. Harvard Business Review 52: 90-102.

Kibbutz Industry Association (KIA). 1999. Enterprises' List: KIA May 1999. Kibbutz Industry Association: Tel Aviv, Israel.

Kibbutz Industry Association (KIA). 2001. http:// www.kia.co.il/fabout.htm (March 16, 2001).

Klein AS, Masi RJ, Weidner II CK. 1995. Organization culture, distribution and amount of control, and perceptions of quality: an empirical study of linkages. Group and Organization Management 20(2): $122-148$.
Lado AA, Wilson MC. 1994. Human resource systems and sustained competitive advantage: a competencybased perspective. Academy of Management Review 19(4): 699-727.

Lipovetsky S, Tishler A, Dvir D, Shenhar A. 1997. The relative importance of success dimensions of defense projects. $R \& D$ Management 27: 97-106.

Mahoney JT. 1995. The management of resources and the resources of management. Journal of Business Research 33: 91-101.

Marcoulides GA, Heck RH. 1993. Organizational culture and performance: proposing and testing a model. Organization Science 4(2): 209-225.

Markides CC, Williamson PJ. 1994. Related diversification, core competencies and corporate performance. Strategic Management Journal 15 (Special Issue): 149-166.

McGuire J, Sundgren A, Schneeweiss T. 1988. Corporate social responsibility and firm financial performance. Academy of Management Journal 31(4): 854-872.

Miller D, Droge C. 1986. Psychological and traditional determinants of structure. Administrative Science Quarterly 31: 539-560.

Miller D, Shamsie J. 1996. The Resource-based view of the firm in two environments: the Hollywood film studios 1936 to 1965. Academy of Management Journal 39(3): 519-543.

Norburn D, Birley S. 1988. The top management team and corporate performance. Strategic Management Journal 9: 225-237.

Penrose ET. 1959. The Theory of the Growth of the Firm. Basil Blackwell: Oxford.

Peteraf MA. 1993. The cornerstones of competitive advantage: a resource-based view. Strategic Management Journal 14: 179-191.

Petty MM, Cashman JF, Seers A, Stevenson RL, Barker CW, Cook G. 1989. Better communication at General Motors. Personnel Journal (September): 40-49.

Pfeffer J. 1994. Competitive advantage through people: unleashing the power of the work force. Harvard Business School Press: Boston, MA.

Porter ME. 1980. Competitive Strategy: Techniques for Analyzing Industries and Competitors. The Free Press: New York.

Prahalad CK, Hamel G. 1990. The core competence of the corporation. Harvard Business Review (MayJune): 79-91.

Priem RL, Butler JE. 2001. Is the resource-based 'view' a useful perspective for strategic management research? Academy of Management Review 26(1): 22-40.

Putti JM, Aryee S, Phua J. 1990. Communication relationship satisfaction and organizational commitment. Group \& Organization Studies 15(1): 44-52.

Reed R, DeFillippi RJ. 1990. Causal ambiguity, barriers to imitation, and sustainable competitive advantage. Academy of Management Review 15(1): 88-102.

Roberts PW, Dowling GR. 1997. The value of a firm's corporate reputation: How reputation helps attain and sustain superior profitability. Corporate Reputation Review 1: 72-76. 
Robins J, Wiersema MF. 1995. A resource-based approach to the multibusiness firm: empirical analysis of portfolio interrelationships and corporate financial performance. Strategic Management Journal 16: 277-299.

Schultz TW. 1961. Investment in human capital. American Economic Review 51(1): 1-17.

Segev E. 1987. Strategy, strategy making, and performance-an empirical investigation. Management Science 22(2): 258-269.

Shrum W, Wuthnow R. 1988. Reputational status of organizations in technical systems. American Journal of Sociology 93(4): 882-912.

Smidts A, Pruyn Ad. ThH, van Riel CBM. 2001. The impact of employee communication and perceived external prestige on organizational identification. Academy of Management Journal 44(5): 1051-1062.

Smith KG, Smith KA, Olian JD, Sims Jr. HP, O'Bannon, DP, Scully JA. 1994. Top management team demography and process: the role of social integration and communication. Administrative Science Quarterly 39: 412-438.

Smith S. 1990. America's most admired corporations. Fortune (January 1): 30-46.

Teece DJ. 2000. Strategies for managing knowledge assets: the role of firm structure and industrial context. Long Range Planning 33(1): 35-54.

Teece DJ, Pisano G, Shuen A. 1997. Dynamic capabilities and strategic management. Strategic Management Journal 18(7): 509-533.

Timm NH. 1975. Multivariate Analysis with Application in Education and Psychology. Brooks: California.

Tishler A, Dvir D, Shenhar A, Lipovetsky S. 1996. Identifying critical success factors of defense development projects: a multivariate analysis. Technological Forecasting and Social Change 51(2): 151-171.

Tishler A, Lipovetsky S. 2000. Modeling and forecasting with robust canonical analysis: method and application. Computers \& Operations Research 27: 217-32.
Tucker ML, Meyer GD, Westerman JW. 1996. Organizational communication: development of internal strategic competitive advantage. Journal of Business Communication 33(1): 51-69.

van Riel CBM. 2000. Corporate communication orchestrated by a sustainable corporate story. In The Expressive Organization: Linking Identity, Reputation, and the Corporate Brand, Schultz M, Hatch MJ, Larsen MH (eds). Oxford: Oxford University Press: 157-181.

Wagner FR, Morse JJ. 1975. A measure of individual sense of competence. Psychological Reports 36: 451-459.

Waldman DA, Ramirez GG, House RJ, Furanam P. 2001. Does leadership matter? CEO leadership attributes and profitability under conditions of perceived environmental uncertainty. Academy of Management Journal 44(1): 134-143.

Wegelin AJ. 2000. A survey of Partial Least Squares (PLS) methods, with emphasis on the two-block case. Technical Report 371, Department of Statistics, University of Washington, Seattle.

Weigelt K, Camerer C. 1988. Reputation and corporate strategy: a review of recent theory and applications. Strategic Management Journal 9: 443-454.

Wernerfelt B. 1984. The resource-based view of the firm. Strategic Management Journal 5: 171-180.

Williamson OE. 1975. Markets and Hierarchies: A study in the Economics of Internal Organization. The Free Press: New York.

Wright PM, Dunford BB, Snell SA. 2001. Human resources and the resource based view of the firm. Journal of Management 27: 701-721.

Yeoh P, Roth K. 1999. An empirical analysis of sustained advantage in the U.S. pharmaceutical industry: impact of firm resources and capabilities. Strategic Management Journal 20: 637-653.

Yukl GA. 1981. Leadership in Organizations. PrenticeHall: Englewood Cliffs, NJ. 